\title{
ORTA ANADOLU BÖLGESİ ATMOSFER-KABUK ARA YÜZEYİ KABUK YOĞUNLUĞUNUN FRAKTAL BOYUTLAR İLE BELİRLENMESİ
}

\author{
Ezgi ERBEK*, Erdinç ÖKSÜM, M. Nuri DOLMAZ
}

Süleyman Demirel Üniversitesi, Mühendislik Fakültesi, Jeofizik Mühendisliği Bölümü, Isparta, Türkiye

\begin{tabular}{l}
\hline Anahtar Kelimeler \\
\hline Fraktal Yöntem, \\
Bouguer Gravite Anomalisi, \\
Orta Anadolu.
\end{tabular}

\begin{abstract}
Öz
Bu çalışma, Orta Anadolu bölgesine ait Serbest Hava Gravite verisindeki topoğrafik etkileri rejyonal ölçekte en aza indirgeyen atmosfer-kabuk ara yüzeyi kabuk yoğunluğu değerinin belirlenmesini amaçlamıştır. Bu amaç doğrultusunda bölgenin yükseklik verileri kullanılarak Serbest Hava Gravite verilerinin çeşitli kabuk yoğunluğu değerleri için topoğrafik etkilerinin indirgemesi yapılmış ve uygulanan her bir yoğunluk değerine ilişkin basit Bouguer Gravite anomalileri elde edilerek bunların Fraktal boyutları hesaplanmıștır. İndirgeme işlemlerinde kullanılan değişken kabuk yoğunluğu değerlerine karşılık elde edilen basit Bouguer Gravite anomalilerinin Fraktal boyutlarının grafiksel analizleri sonucunda Orta Anadolu bölgesi Serbest Hava Gravite verilerindeki topoğrafik etkiyi rejyonal ölçekte minimize eden atmosfer-kabuk ara yüzeyi kabuk yoğunluğu değeri $2.59 \mathrm{gr} / \mathrm{cm}^{3}$ olarak hesaplanmıștır.
\end{abstract}

\section{DETERMINATION OF ATMOSPHERE-CRUST INTERFACE CRUSTAL DENSITY OF THE CENTRAL ANATOLIA REGION BY THE FRACTAL DIMENSIONS}

\section{Keywords \\ Fractal Method, \\ Bouguer Gravity Anomalies, \\ Central Anatolia.}

\begin{abstract}
This study aimed to determine the crustal density value at the atmosphere-crust interface that minimizes the topographic effects in the free air gravity data of the Central Anatolia region on a regional scale. For this purpose, using the elevation data of the region, topographic effects were reduced for various crustal density values of Free Air Gravity data and fractal dimensions were calculated of the simple Bouguer Gravity anomalies obtained for each density value. As a result of the graphical analysis of the fractal dimensions of the simple Bouguer Gravity anomalies obtained in response to the variable crustal density values used in the reduction processes, the crustal density value at the atmosphere-crust interface, which minimizes the topographic effect in the free air gravity data on a regional scale, was calculated as $2.59 \mathrm{gr} / \mathrm{cm}^{3}$ for the Central Anatolia region.
\end{abstract}

\section{Alıntı / Cite}

Erbek, E., Öksum, E., Dolmaz, M.N., (2020). Orta Anadolu Bölgesi Atmosfer-Kabuk Ara Yüzeyi Kabuk Yoğunluğunun Fraktal Boyutlar ile Belirlenmesi, Mühendislik Bilimleri ve Tasarım Dergisi, 8(3), 703-711.

\begin{tabular}{l|l|l}
\hline Yazar Kimliği / Author ID (ORCID Number) & \multicolumn{3}{|l}{ Makale Süreci / Article Process } \\
\hline E. Erbek, 0000-0003-4627-8932 & Başvuru Tarihi / Submission Date & 10.04 .2020 \\
E. Öksüm, 0000-0001-8386-9411 & Revizyon Tarihi / Revision Date & 02.06 .2020 \\
M. N. Dolmaz, 0000-0002-9185-9835 & Kabul Tarihi / Accepted Date & 01.07 .2020 \\
& Yayım Tarihi / Published Date & 24.09 .2020 \\
\hline
\end{tabular}

\section{Giriş (Introduction)}

Gravite verileri ve bunlara ilişkin çeșitli jeofizik analiz yöntemleri, belirli bir bölgenin jeolojik ve tektonik haritalarının oluşturulmasında, ekonomik yeraltı kaynaklarının araştırılmasında, çevre ve mühendislik uygulamalarında önemli bilgiler sağlayabilmektedir (Kaftan vd., 2005; Albora vd., 2007; Oruç, 2014; Ekinci ve Yiğitbaş, 2015; Ekinci vd., 2016). Özellikle geniş çalışma alanlarını kapsayan petrol amaçlı çalışmalarda sedimanter havzaların modellenmesi (Öksüm vd., 2019) ve havza içerisinde petrol potansiyeli bulunabilecek

\footnotetext{
* ilgili yazar / Corresponding author: ezgierbek@sdu.edu.tr, +90-246-211-1368
} 
yeraltı jeolojik yapı unsurlarının aydınlatılmasında sıklıkla başvurulan gravite verileri araştırma maliyetlerine kazanım sağlayan önemli bir rol üstlenmektedir.

Ölçülen gravite değerleri, yer altında yoğunluk farkları ilkesine göre jeolojik yapıların yer çekim etkilerinin yanı sıra, dünyanın şekline bağlı gravite etkilerini de içermektedir. Dolayısıyla gravite değişimlerinin analizi öncesinde ölçülen gravite verilerine birtakım indirgeme işlemleri uygulanarak çalışma amacına uygun verilerin elde edilmesi amaçlanır. Yapılan bu düzeltme aşamalarından biri olan Bouguer düzeltmesi, serbest havaya indirgenen gravite verilerine etki eden referans düzlemi üzerindeki kütlelerin yer çekim etkilerinin giderilmesidir. Bu etkilerin giderilmesinde ise referans düzlemi üzerindeki kütlelerin yoğunluk değerlerine ihtiyaç duyulmaktadır. Küresel veya bölgesel çalışmalarda bu yoğunluk değeri genellikle $2.67 \mathrm{gr} / \mathrm{cm}^{3}$ olarak varsayılır (ör., LaFehr, 1991; Hinze vd., 2005). Yerel çalışmalarda ise düzeltme yoğunluğu verilen alandaki gerçek bir topoğrafik kaya yoğunluğunu temsil etmelidir.

Bu çalışmada yukarıda verilen bilgiler doğrultusunda Fraktal yöntem kullanılarak Orta Anadolu bölgesi serbest hava gravite verilerindeki topoğrafik etkileri bölgesel ölçekte en aza indirgeyen Bouguer yoğunluk değerinin tahmini yapılmıştır. Şekil 1 çalıșma alanını kapsayan Orta Anadolu bölgesinin 2'×2' çözünürlülüğündeki topoğrafik haritasını ve Şekil 2 Bureau Gravimétrique International'ın (BGI) web sitesinden (http://bgi.omp.obsmip.fr/data169 products/Grids-and-models/wgm2012) elde edilen 2'×2' çözünürlüğündeki Serbest Hava Gravite anomali verilerinin haritasını göstermektedir.

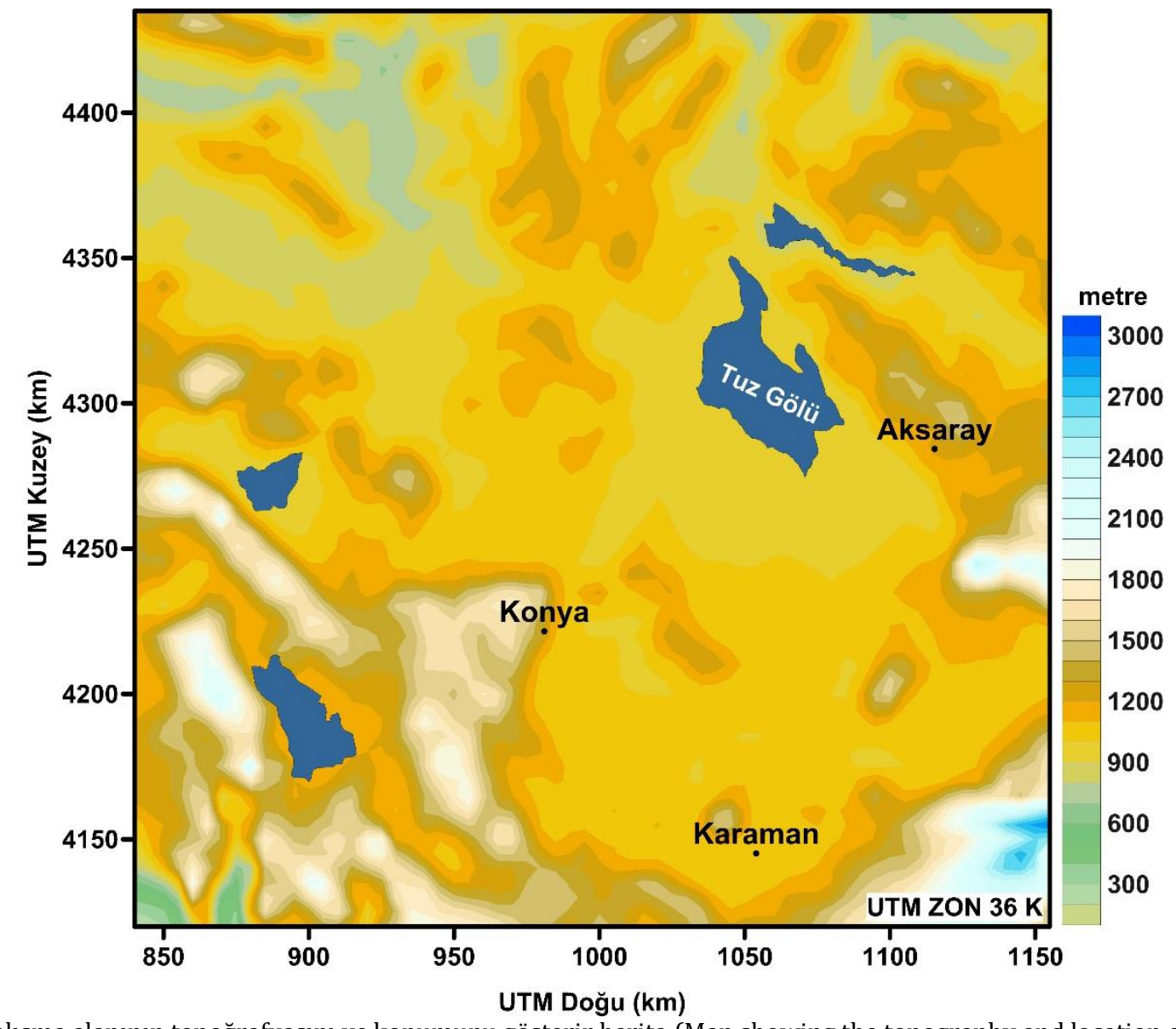

Şekil 1. Çalışma alanının topoğrafyasını ve konumunu gösterir harita (Map showing the topography and location of the study area) 


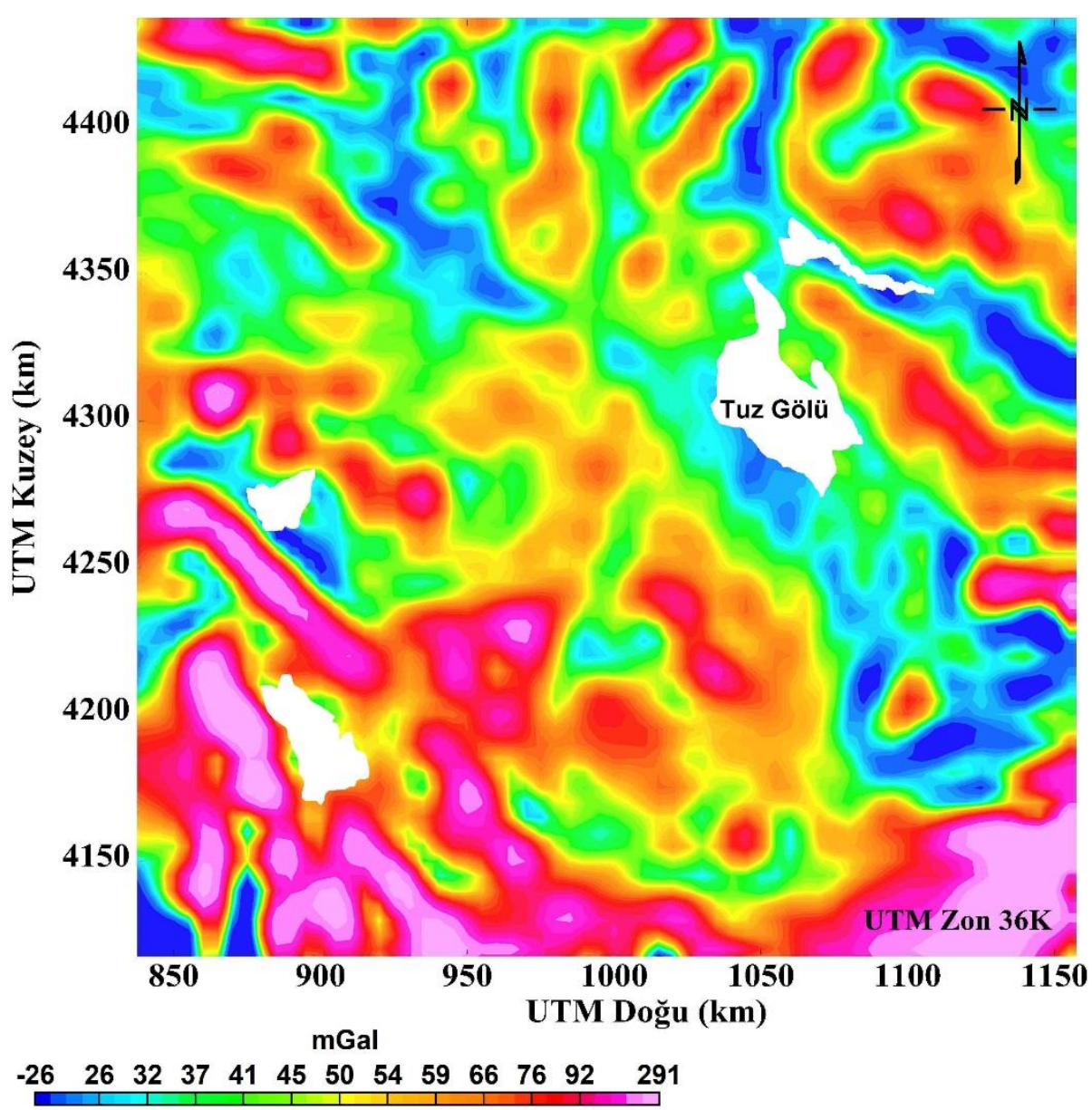

Şekil 2. Çalışma alanına ait Serbest Hava Gravite anomali haritası (http://bgi.omp.obs-mip.fr/data169 products/Grids-andmodels/wgm2012) (Free Air Gravity anomaly map of the study area)

\section{Kaynak Araștırması (Literature Survey)}

Serbest Hava Gravite anomali haritalarındaki topoğrafik etkileri en aza indirgemek için bölgeyi temsil eden optimum Bouguer düzeltme yoğunluğunun tahmini için doğrudan laboratuvar ortamı yoğunluk ölçümleri dışında pek çok sayısal ve istatiksel yöntem önerilmiştir. Nettleton (1942) Bouguer düzeltme yoğunluğunun tahmini için doğrudan yüzey gravite ölçümlerinden yararlanarak Bouguer Gravite anomalisi ve yükseklik korelasyonu temeline dayanan bir profil yöntemi önermişlerdir. Fakat bu yöntem, izostatik etkiler gibi büyük dalga boylu etkileri ihmal etmesi nedeniyle daha çok kabuk yoğunluğunun yanal varyasyonlar ile desteklendiği varsayılan küçük ölçekli bölgeler için önerilir (Tontini vd., 2007). Diğer yandan yöntemin Bouguer yoğunluk tahmininde başarısı için bazı saha kriterlerinin sağlanması gerekir (Torge, 1989; Yamamoto, 1999). Kuyu içi gravimetrik ölçümler yerinde kaya yoğunluklarının tahmininde kullanılan diğer uygulamalardır (örn. Hammer, 1950; Gibb ve Thomas, 1980; LaFehr, 1983). Sissons (1981), yüzey ve yüzey altı gravite ölçümlerini kullanarak yerinde yoğunluk tahmini için en küçük kareler esasına dayanan bir ters çözüm yöntemi sunmuștur. Bununla birlikte, yer altı gravite ölçümleriyle ilişkili bu yöntemler yalnızca homojen kaya birimlerinin olduğu oldukça sınırlı alanlar için geçerlidir. Daha sonraları sadece yüzey gravite verilerinin kullanımı ile yoğunluk tespiti için Bouguer Gravite anomalisi, Serbest Hava Gravite anomalisi, ölçü yükseklikleri ve indirgeme yoğunlukları arasındaki korelasyonları esasına dayanan farklı istatiksel yöntemler de geliştirilmiştir (örn., Parasnis, 1952; Rikitake vd., 1965; Fukao vd., 1981; Murata, 1993). Diğer yandan, çok büyük ölçekli çalışma alanları için tek bir Bouguer yoğunluğu değeri yerine çalışma alanını alt pencerelere bölerek her bir alt bölgenin Bouguer yoğunluğunun ayrı olarak bulunmasına yönelik yöntemler de sunulmuştur (örn, Rimbert vd., 1987; Moribayashi, 1990). Yakın geçmişte, Thorarinsson ve Magnusson (1990), Serbest Hava Gravite Anomalilerindeki topoğrafik etkileri minimize eden Bouguer yoğunluğu değerinin tahmini için gravite anomalilerinin Fraktal boyutları analizinden yararlanılan bir yöntem önermişlerdir. Daha sonrasında araştırmacıların sunduğu bu yöntemi Chapin (1996) geliştirerek kıtasal ölçekte Güney Amerika gravite verilerine uygulamışlardır. Ülkemizde, Hisarlı ve Orbay (2001) ise, Batı Anadolu bölgesi için Fraktal yöntemini kullanarak bölgenin atmosfer - kabuk ara yüzeyi yoğunluk değerini $2.58 \mathrm{gr} / \mathrm{cm}^{3}$ olarak belirlemişlerdir. Oksum ve Hisarlı (2011) yine Fraktal yöntem ile Doğu Anadolu bölgesi Bouguer yoğunluk değerini $2.43 \mathrm{gr} / \mathrm{cm}^{3}$ olarak hesaplamışlardır. 


\section{Materyal ve Yöntem (Material and Method)}

\subsection{Jeolojik Özellikler (Geological Settings)}

Çalışma alanını kapsayan Orta Anadolu bölgesi kuzeyde Kuzey Anadolu Fay Zonu (KAFZ), Doğuda Doğu Anadolu Fay Zonu (DAFZ), batıda Ege Graben Sistemi ve güneyde Toroslar ile çevrelenmiştir. Alp-Himalaya dağ kuşağı üzerinde yer alan Anadolu yoğun bir deformasyona maruz kalmaktadır. Çalışma alanının güneyinde yer alan Toroslar ile Orta Anadolu birbirinden Geç Kretase - Paleosen yaşlı yüksek basınca maruz kalmış metamorfik birimler ile ayrılmaktadır ( Okay vd., 1998; Candan vd., 2005; Lefebvre vd., 2011).

Orta Anadolu'da kristalin ve plütonik birimlerden oluşan Kırşehir Masifi, Sakarya Masifi ve Akdağ Masifi bölgenin temelini oluşturmaktadır. Ayrıca, yüzlekler veren Senozoyik yaşlı volkanlar da yaygın olarak görülmektedir. Pliyosen yaşlı volkanizma ise özellikle Konya ve Karaman civarında yüzlekler vermiștir. Karaman'ın kuzey kesiminde kalkalkalen andezitik-bazaltik, andezitik ve dasitik bir volkanizma görülmektedir. Hasan Dağı ve Melendiz Dağlarının olduğu bölgede ki volkanizma ise Orta Miyosende başlamış Hasan Dağı'nın kuvaterner yaşlı bazaltik lavlarıyla sonlamıştır (Pasquare, 1966; Ercan, 1986).

\subsection{Fraktal Yöntem (Fractal Method)}

Doğadaki birçok nesne, klasik geometrinin basit șekilleri ile temsil edilememektedir. Örneğin bir dağ yapısı her ne kadar genel hatları ile bir konik şekil ile ifade edilebilse de, her yönündeki yüzeylerinin girintiler ve çıkıntılar içermesi onu basit bir geometrik şekilden oldukça farklı kılmaktadır (Matt, 1977). Bununla birlikte, doğadaki bir çok nesne, matematiksel olarak bir öz-benzerliği ifade eden fraktal ölçüleriyle ifade edilebilmektedir. Burada özbenzerlik, nesnenin küçük bir bölümünün çoğu kez tüm nesnenin küçük bir kopyası gibi görünmesi anlamına gelir. Pek çok jeolojik olay, fraktal bir özellik sergiler (örneğin kıyı çizgisi, topoğrafya, lav akıntıları). Fraktal olaylar skala bağımsız fiziksel olgular olup yapılan ölçümlerin fiziksel olguya karşı çizimlerinden elde edilir. Eğer fiziksel bir olgu fraktal ise, çeşitli skalalar için elde edilen çizim doğrusal bir segment oluşturur ve bunun eğiminden hesaplanan fraktal boyut, D, veri ve sistemin karmaşıklığının bir ölçüsü olan fraktal özelliğini verir.

Serbest Hava Gravite anomali verileri, yeraltındaki jeolojik yapıların etkisi beraberinde topoğrafik kütlelerin etkisini de içermektedir. Burada topoğrafik etkinin hesaplanmasında yükseklik parametresi fraktal bir olgu ve skala bağımsız bir bileşen, buna karşın kütle yoğunluğu skala bağımlı bir bileşendir (Mark ve Aronson, 1984; Turcotte, 1992). Bu fiziksel olgudan haraket ile gravite verisi içerisinde topoğrafik etkiyi indirgemek için fraktal özellikten yararlanarak topoğrafik etkiye neden olan Bouguer düzeltme yoğunluğu sayısal olarak hesaplanabilmektedir.

Bu çalışmada, Orta Anadolu bölgesi Serbest Hava Gravite verisindeki topoğrafik etkiyi en aza indirgeyen Bouguer düzeltme yoğunluğunun belirlenmesi için (Chapin, 1996) tarafından uygulanan Fraktal yöntemi kullanılmıştır. Buna göre, bir veri sisteminin fraktal boyutu D, güç spektrumu yöntemi ile (Barton vd., 1991) aşağıdaki gibi verilmektedir:

$$
\mathrm{D}=(9+\beta) / 2
$$

Burada $\beta$, verinin log-log ölçeğinde radyal ortalama güç spektrumunun doğrusal dağılım gösteren segmentine geçirilen bir doğrunun eğimidir.

Chapin (1996), önerdiği yöntemde, ilk olarak Serbest Hava Gravite verilerini sistematik olarak artan farklı yoğunluk değerleri için Bouguer düzeltmesini yaparak her bir düzeltme yoğunluğu değerine ilişkin bir Basit Bouguer anomalisi (BBA)

$$
\mathrm{BBA}=\mathrm{SHA}-2 \pi G \rho h
$$

elde etmektedir. Burada SHA Serbest Hava Gravite verisini, G evrensel gravitasyon sabitini, h yükseklik değerini ve $\rho$ Bouguer düzeltme yoğunluğunu simgelemektedir. Daha sonra farklı $\rho$ değerleri kullanılarak elde edilen her bir BBA için verinin radyal güç spektrumu alınır ve bunların kısa dalga boylarında doğrusal dağılım gösteren segmentlerine bir doğru geçirilerek doğruların eğim değerleri ( $\beta$ ) Eşitlik (1)'de kullanılır ve anomalilerin Fraktal boyutları (D) hesaplanarak bir $\rho$-D grafiği oluşturulur. Eşitlik (2)'de $2 \pi G \rho$ terimi, serbest hava anomalisinin skala bağımlı bileşeni, $h$ yükseklik terimi ise anomalinin skala bağımsız fraktal bileşeni olmaktadır. Kullanılan düzeltme yoğunluğu $\rho$ değeri arrtıkça, BBA anomalisinde skala bağımlı bileșen baskın olmakta, buna karşın fraktal özellik azalmaktadır. Dolayısıyla elde edilen $\rho$ - $D$ grafiği artan yoğunluk değerlerine karşılık azalan fraktal boyutlar ile 
karakterizedir. Chapin (1996), Serbest Hava anomalisinin fraktal özelliğini veya diğer bir değiş ile topoğrafik etkiyi minimize eden en uygun Bouguer düzeltme yoğunluğunun belirlenmesinde ölçüt olarak, $\rho$ - $D$ grafiğindeki $\mathrm{D}$ eğrisi ile buna geçirilen lineer bir doğrunun denkleminden elde edilen değerleri arasındaki farkların kullanılmasını önermiştir. Buna göre bir U şekli oluşturan rezidüel fraktal boyutlar eğrisinin minimum değerine karşılık gelen yoğunluk değeri, SHA verisindeki topoğrafik etkiyi minimize eden yoğunluk değeri olarak tanımlanmaktadır.

\section{Bulgular (Results)}

Çalışmada bölgenin Serbest Hava Gravite verileri ve topoğrafya verileri kullanılarak 2.2-3.0 gr/ $\mathrm{cm}^{3}$ aralığında ve $0.01 \mathrm{gr} / \mathrm{cm}^{3}$ artım miktarı ile değişen Bouguer yoğunluk değerleri için bölgenin Serbest Hava Gravite anomali verileri Eşitlik (2) ile Bouguer düzeltmesi yapılarak her bir yoğunluk değerine ilişkin 81 farklı basit Bouguer Gravite anomalileri elde edilmiştir. Daha sonra her bir basit Bouguer Gravite anomalisinin radyal ortalama güç spektrumları hesaplanarak kısa dalga boylarında doğrusal dağılım görülen segmentlerine geçirilen doğruların eğimleri ( $\beta$ ) Eşitlik (1)'de kullanılarak anomalilerin fraktal boyutları hesaplanmıştır. Şekil 3a-c, sırasıyla 2.2 $\mathrm{gr} / \mathrm{cm}^{3}, \quad 2.6 \mathrm{gr} / \mathrm{cm}^{3}$ ve $3.0 \mathrm{gr} / \mathrm{cm}^{3}$ düzeltme yoğunluk değerleri için hesaplanan basit Bouguer Gravite anomalilerinin radyal ortalama güç spektrumlarını ve bunların doğrusal segmentlerine geçirilen doğruların eğim değerlerini ve bunlardan hesaplanan fraktal boyut değerlerini örnek olarak göstermektedir. Örneğin Şekil 3a'da, $2.2 \mathrm{gr} / \mathrm{cm}^{3}$ Bouguer düzeltme yoğunluğu için elde edilen basit Bouguer anomalisinin radyal güç spektrumu değerlerinin doğrusal segmentine geçirilen doğrunun eğimi $\beta=-4.3940$ değeri Eşitlik (1)' de kullanılarak verinin fraktal boyutu $\mathrm{D}=2.3030$ olarak hesaplanmıștır. Tüm Bouguer düzeltme yoğunluklarına ilişkin basit Bouguer anomalilerinden elde edilen fraktal boyutların kullanılan yoğunluk değerlerine karşın grafiği Şekil 4'de gösterilmiştir.

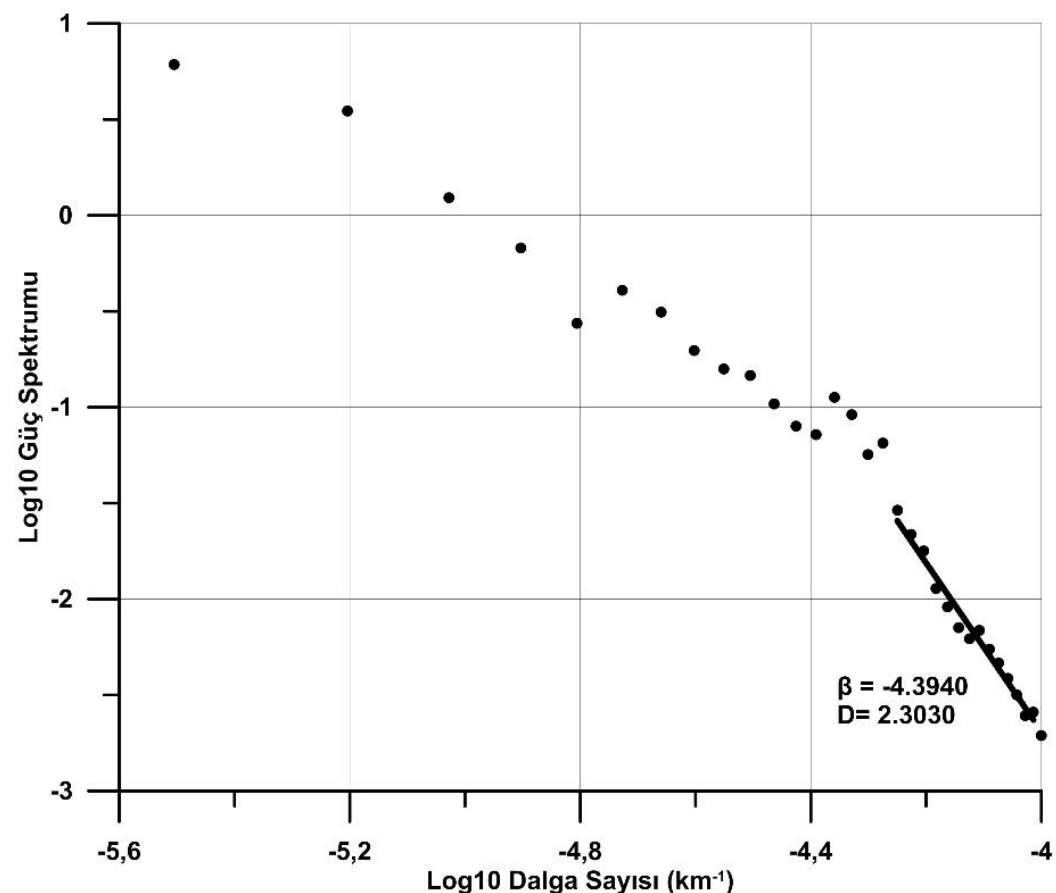

Şekil 3.a) $2.2 \mathrm{gr} / \mathrm{cm}^{3}$ yoğunluk değeri için hesaplanan basit Bouguer Gravite anomalilerinin güç spektrumu ve elde edilen fraktal boyutu (Power spectrum of simple Bouguer Gravity anomalies calculated for the density value of $2.2 \mathrm{gr} / \mathrm{cm}^{3}$ and its fractal dimension obtained) 


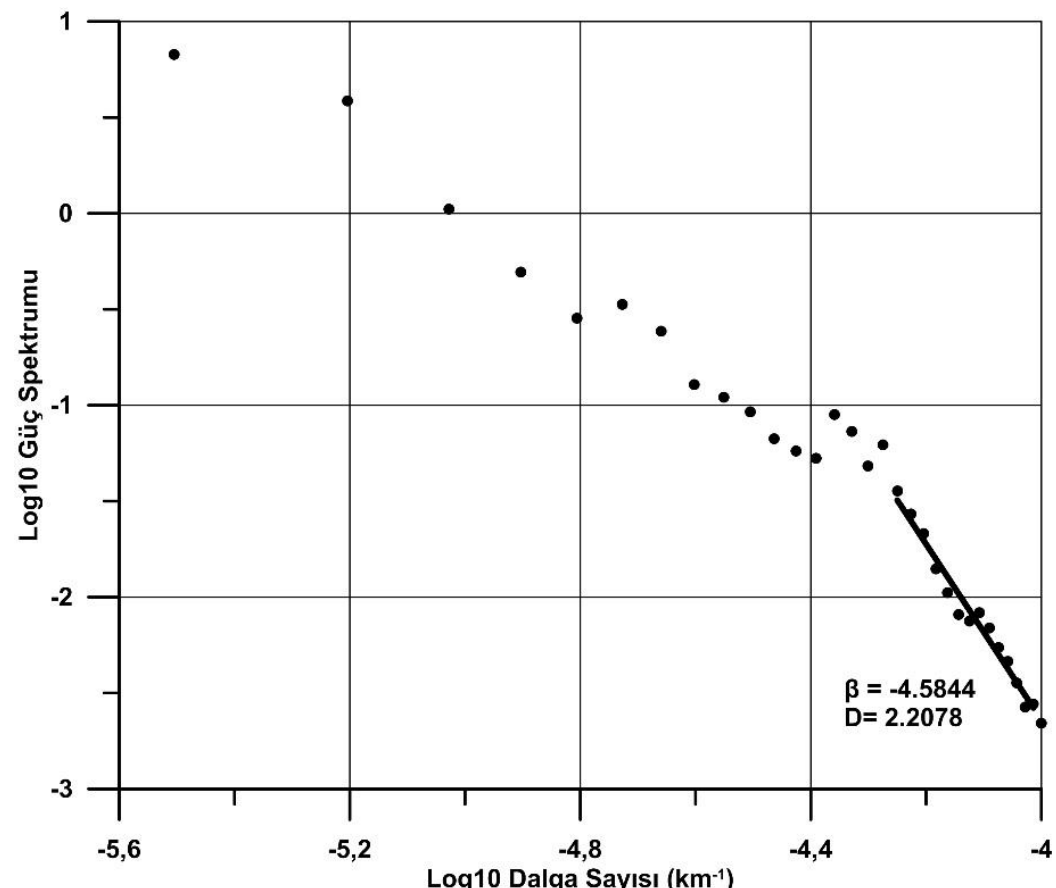

Şekil 3.b) $2.6 \mathrm{gr} / \mathrm{cm}^{3}$ yoğunluk değeri için hesaplanan basit Bouguer Gravite anomalilerinin güç spektrumu ve elde edilen fraktal boyutu (Power spectrum of simple Bouguer Gravity anomalies calculated for the density value of $2.6 \mathrm{gr} / \mathrm{cm}^{3}$ and its fractal dimension obtained)

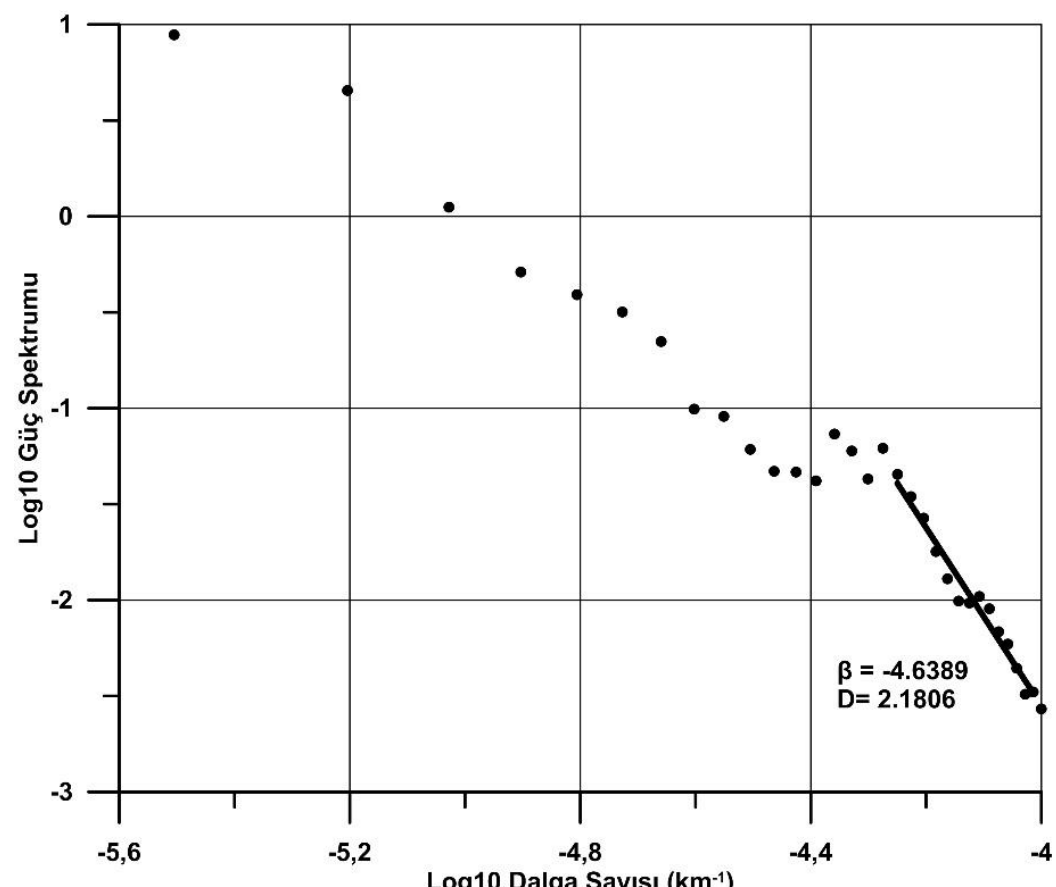

Şekil 3.c) $3.0 \mathrm{gr} / \mathrm{cm}^{3}$ yoğunluk değeri için hesaplanan basit Bouguer Gravite anomalilerinin güç spektrumu ve elde edilen fraktal boyutu (Power spectrum of simple Bouguer Gravity anomalies calculated for the density value of $3.0 \mathrm{gr} / \mathrm{cm}^{3}$ and its fractal dimension obtained) 


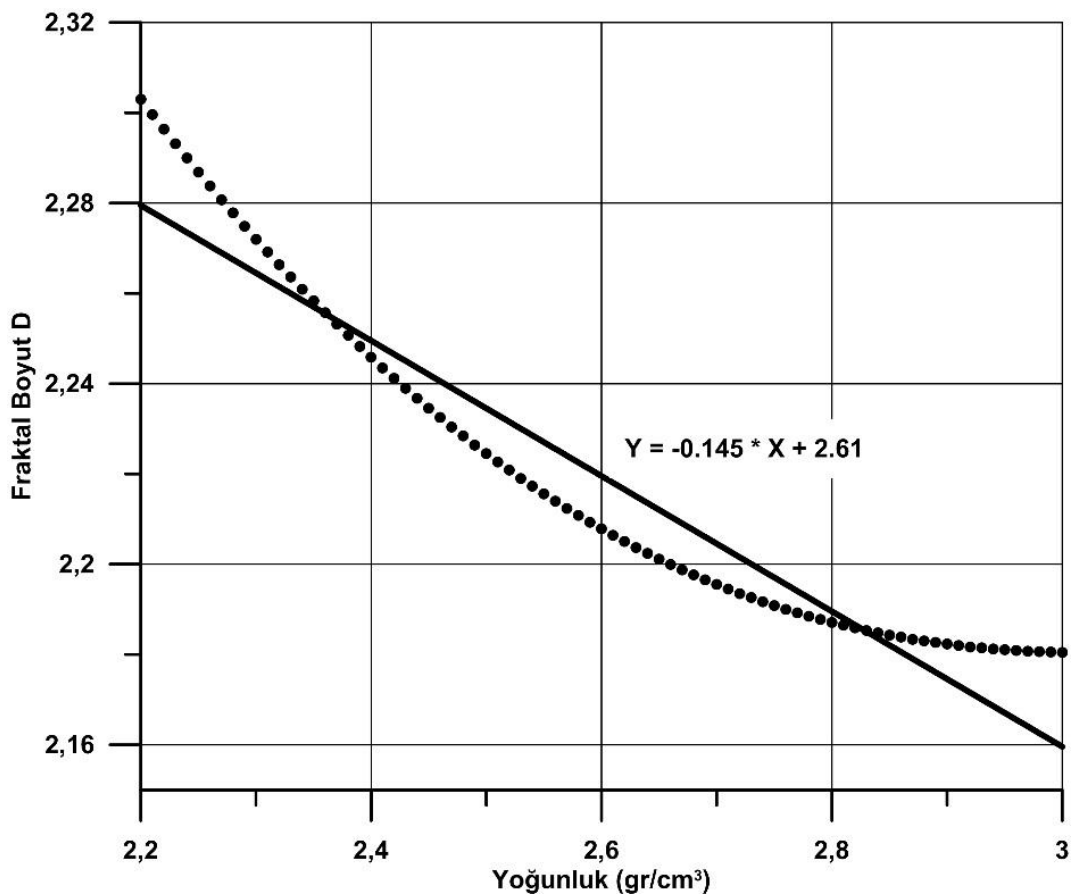

Şekil 4. 2.2 - $3.0 \mathrm{gr} / \mathrm{cm}^{3}$ aralığında farklı Bouguer düzeltme yoğunluklarına karşı Bouguer Gravite anomalilerinden hesaplanan fraktal boyutlar eğrisi ve buna uydurulan doğrunun denklemi (Fractal dimensions curve calculated from Bouguer Gravity anomalies against different Bouguer correction densities in the range of $2.2-3.0 \mathrm{gr} / \mathrm{cm}^{3}$ and the linear curve fitting equation)

Daha sonra Şekil 4' de artan yoğunluk ve azalan fraktal boyut (D) ilişkisine (siyah noktalı eğri) en küçük kareler yöntemi ile bir doğru geçirilerek kullanılan yoğunluk değerleri için doğrunun sayısal denklem değerleri $(Y=$ $-0.145 X+2.61$ ) hesaplanmıştır. $2.2-3.0 \mathrm{gr} / \mathrm{cm}^{3}$ aralığı için basit Bouguer anomalilerinden hesaplanan fraktal boyutlar ile doğru denkleminden elde edilen fraktal boyutlar arasındaki farkların grafiği (rezidüel fraktal boyutlar) Şekil 5'de gösterilmiștir. Buna göre, değișen Bouguer düzeltme yoğunlukları için elde edilen rezidüel fraktal boyutların en küçük değerine karşılık gelen yoğunluk değeri, bölgenin topoğrafik etkilerini minimize eden Bouguer yoğunluk değerini vermektedir. Bu çalışmada Orta Anadolu bölgesini kapsayan çalışma alanı için topoğrafik etkiyi minimize eden Bouguer yoğunluk değeri fraktal boyutlar yöntemi ile $2.59 \mathrm{gr} / \mathrm{cm}^{3} \mathrm{olarak}$ hesaplanmıştır (Şekil 5).

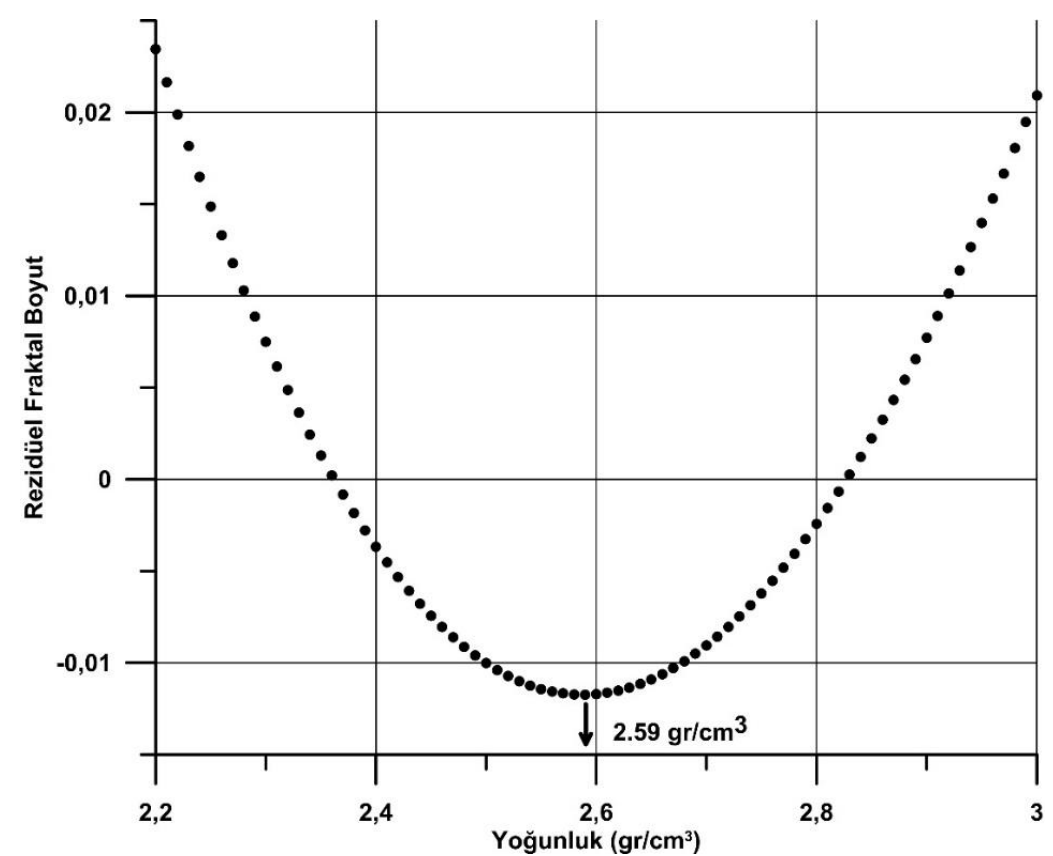

Şekil 5. Rezidüel fraktal boyutların yoğunluk değişimine karşı çizimi (Plotting of residual fractal dimension versus density variation) 


\section{Sonuçlar ve Tartışma (Conclusions and Discussion)}

Bouguer Gravite anomalileri elde edilirken Serbest Hava Gravite anomalilerinin Bouguer düzeltmesi işlemi, bölgeyi temsil eden en uygun atmosfer-kabuk ara yüzeyi kabuk yoğunluğu değerinin kullanılmasıyla daha etkin olmaktadır. Bu çalıșmada Orta Anadolu bölgesine ait serbest hava gravite anomali verisindeki topoğrafik etkileri rejyonal ölçekte en aza indirgeyen atmosfer-kabuk ara yüzeyi kabuk yoğunluğu değerinin Fraktal yöntem ile belirlenmesi amaçlanmıştır. Bu amaç doğrultusunda çalışma alanının yükseklik değerleri kullanılarak Serbest Hava Gravite anomali verilerinin çeşitli kabuk yoğunluğu değerleri için topoğrafik etkilerinin indirgemesi yapılmış ve uygulanan her bir yoğunluk değerine ilişkin basit Bouguer Gravite anomalileri elde edilerek bunların Fraktal boyutları hesaplanmıștır. Elde edilen basit Bouguer Gravite anomalilerinin fraktal boyutlarının grafiksel analizleri sonucunda Orta Anadolu bölgesi Serbest Hava Gravite anomali verilerindeki topoğrafik etkiyi rejyonal ölçekte minimize edecek olan kabuk yoğunluğu değeri $2.59 \mathrm{gr} / \mathrm{cm}^{3}$ olarak elde edilmiștir.

Ateş vd., (1999) tüm Türkiye için Bouguer Gravite anomali haritasını daha önce MTA tarafından hazırlanan haritalarda kullanılan $2.67 \mathrm{gr} / \mathrm{cm}^{3}$ yoğunluk değeri yerine, $2.4 \mathrm{gr} / \mathrm{cm}^{3}$ yoğunluk değerini kabul ederek ve kullanarak hazırlamışlardır. Araștırmacılar sundukları haritada topoğrafik etkinin tamamen giderildiğini vurgulamışlardır. Fraktal yöntem ile atmosfer - kabuk ara yüzeyi yoğunluk değerini belirlemeye yönelik önceki çalışmalarda Batı Anadolu bölgesi için $2.58 \mathrm{gr} / \mathrm{cm}^{3}$ (Hisarlı ve Orbay, 2001), Doğu Anadolu bölgesi için $2.43 \mathrm{gr} / \mathrm{cm}^{3}$ (Öksüm ve Hisarlı, 2011) Bouguer yoğunluk değerleri hesaplanmıştır. Bu çalışmada Orta Anadolu bölgesi için elde edilen Bouguer yoğunluk değeri Batı Anadolu bölgesi için elde edilen değer ile uyumludur.

\section{Teşekkür (Acknowledgement)}

Yazarlar, Sorumlu Editör ve makalenin incelenmesi neticesinde geliştirilmesine yönelik değerli görüşlerini belirten hakemlere teșekkür ederler.

\section{Çıkar Çatışması (Conflict of Interest)}

Yazarlar tarafından herhangi bir çıkar çatışması beyan edilmemiştir. No conflict of interest was declared by the authors.

\section{Kaynaklar (References)}

Albora, A. M., Ucan, O. N., Aydoğan, A. 2007. Tectonic Modeling of Konya-Beysehir Region (Turkey) Using Cellular Neural Networks, Annals of Geophysics, 50, 5, 603-614.

Ates A., Kearey, P., Tufan S. 1999. New gravity and magnetic anomaly maps of Turkey. Geophys. J. Int., 136, 499-502.

Barton, C. C., LaPointe, P.R., Malinverno, A. 1991, Short course, notes: fractal geometry and its application to the petroleum industry. Am. Assoc. Petr. Geol. Ann. Mtg.

Candan, O., Cetinkaplan, M., Oberhansli, R., Rimmele, G., Akal, C. 2005. Alpine highpressure low-temperature metamorphism of the Afyon zone and implications for the metamorphic evolution of western Anatolia, Turkey. Lithos, 84 (1-2), 102-124.

Chapin, D.A. 1996. A Deterministic Approach Toward Isostatic Gravity Residuals - A Case Study from South America. Geophysics, 61(4,) 1022-1033.

Ekinci, Y.L., Yiğitbaș, E. 2015. Interpretation of gravity anomalies to delineate some structural features of Biga andGelibolu peninsulas, and their surroundings (north-west Turkey). Geodinamica Acta, 27 (4), 300-319.

Ekinci, Y.L., Balkaya, Ç., Göktürkler, G., Turan, S. 2016. Model parameter estimations from residual gravity anomaliesdue to simple-shaped sources using Differential Evolution Algorithm. Journal of Applied Geophysics, 129, 133-147.

Ercan, T. 1986. Orta Anadolu'daki Senozoyik Volkanizması. MTA Dergisi, 107, 119-140.

Fukao, Y., Yamamoto, A., Nozaki, K. 1981. A method of density determination for gravity correction. J. Phys. Earth, 29, 163-166.

Gibb, R.A., Thomas, M.D. 1980. Density determinations of basic volcanic rocks of the Yellowknife supergroup by gravity measurements in mine shafts-Yellowknife, Northwest Territories. Geophysics, 45(1), 18-31.

Hammer, S. 1950. Density determinations by underground gravity measurements. Geophysics, 15, 637-652.

Hinze W. J., Aiken C., Brozena J., Coakley B., Dater D., Flanagan G., Forsberg R., Hildebrand T., Keller G. R., Kellogg J., Kucks R., Li X., Mainville A., Morin R., Pilkington M., Plouff D., Ravat D., Roman D., Urrutia-Fucugauchi J., Veronneau M., Webring M, Winester D. 2005. New standards for reducing gravity data: The North American gravity database. Geophysics, 70, J25-J32.

Hisarl, M., Orbay, N. 2001. Determination of Crustal Density at The Atmosphere-Crust Interface of Western Anatolia by Using The Fractal Method. Journal of The Balkan Geophysical Society, 5(1), 3-8.

Kaftan, I., Şalk, M., Sarı, C. 2005. Application of the finite element method to gravity data case study: WesternTurkey. Journal of Geodynamics, 39, 431-443.

LaFehr, T.R. 1983. Rock densities from borehole gravity surveys. Geophysics, 48, 341-356.

LaFehr, T.R. 1991. Standardization in gravity reduction. Geophysics, 56, 1170-1178.

Lefebvre, C., Barnhoorn, A.,. Van Hinsbergen, D.J.J., Kaymakci, N., Vissers, R. L.M. 2011. Late Cretaceous Extensional Denudation Along a Marble Detachment Fault Zone in the Kırsehir Massif Near Kaman, central Turkey. Journal of Structural Geology, $33,1220-1236$. 
Mark, D. M., Aronson, P. B. 1984. Scale-dependent fractal dimensions of topographic surfaces: An empirical investigation, with applications in geomorphology and computer mapping, Math. Geol., 16, 671-683.

Matt, B. 1977. Fractal Pattern in Nature: http://www.stanford.edu/ mattb/fracpapr.htm

Moribayashi, S. 1990. A new method for variable density correction of gravity data. BUTSURI-TANSA (Geophys. Explor.), 43, 97-106 (in Japanese with English abstract).

Murata, Y. 1993. Estimation of optimum average surficial density from gravity data: An objective Bayesian approach. J. Geophys. Res., 98, 12097-12109.

Nettleton, L.L. 1942. Gravity and Magnetic Calculations. Geophysics, 7, 293-310.

Okay, A.I., Harris, N.B.W., Kelley, S.P. 1998. Exhumation of blueschists along a Tethyan suture in northwest Turkey. Tectonophysics, 285 (3-4), 275-299.

Oksum, E., Hisarlı Z.M. 2011. Estimation of the avarage crustal density and its contrast to the mantle in the Eastern Anatolia, Turkey. Geophysical Research Abstracts 13, 355s EGU General Assembly 2011

Oksum, E., Dolmaz, M.N., Pham, L.T. 2019. Inverting gravity anomalies over the Burdur sedimentary basin, SWTurkey. Acta Geodaetica et Geophysica, 54, 445-460.

Oruc, B. 2014. Structural interpretation of southern part of western Anatolian using analytic signal of the secondorder gravity gradients and discrete wavelet transform analysis. Journal of Applied Geophysics, 103, 82-98.

Pasquare, G. 1966, Outlines of the Neogene and Quaternary Volcanism of Asia Minör: Accad. Naz. dei Linç., 40, 1077-1085.

Parasnis, D.S. 1952. A study of rock density in the English Midlands. Mon. Not. R. Astron.Soc. Geophys. Suppl., 6, $252-271$.

Rikitake, T., Tajima, H., Izutuya, S., Hagiwara, Y., Kawada, K., Sasai, Y. 1965. Gravimetric and geomagnetic studies of Onikobe area. Bull. Earthquake Res. Inst., Tokyo Univ., 43, 241-267.

Rimbert, F., Erling, J.C., Lakshmanan, J. 1987. Variable density Bouguer processing of gravity data from Herault, First Break, $5(1), 9-13$

Sissons, B.A. 1981, Densities determined from surface and subsurface gravity measurements. Geophysics, 46(11), 1568-1571.

Thorarinsson, F., Magnusson, S.G., 1990. Bouguer density determination by fractal analysis. Geophysics, 55(7), 806-948.

Tontini, F.C., Graziano, F., Cocchi, L., Carmisciano, C., Stefanelli, P. 2007. Determining the optimal Bouguer density for a gravity data set: implications for the isostatic setting of the Mediterranean Sea. Geophys. J. Int., 169, 380-388.

Torge, W. 1989. Gravimetry, Walter de Gruyter, Berlin, New York, 465s.

Turcotte, D.L. 1992. Fractal and Chaos in Geology and Geophysics, Cambridge University Press.

Yamamoto, A. 1999. Estimating the Optimum Reduction Density for Gravity Anomaly: A Theoretical Overview. Jour. Fac. Sci., Hokkaido Univ., Ser. VII. Geophysics, 11(3), 577-599. 